\title{
13 Homes for Refugee Children of the O.S.E. Union in France (1940)
}

Maybe you will be surprised that I'm writing you from France, or maybe you have already heard that I've been in France since March 8th. I feel splendid and am very happy to be out of Germany. I am here with about 57 children in a wonderful home close to Paris, approximately 10 miles from the city. We have an enormous park with two lawns where we play during our free periods. The food is excellent and I have already gained $11 \mathrm{lbs}$ and have become much taller. Bur that is also because of the change of climate.

Early in the morning we have gym. After breakfast we have classes until twelve. We have physics, French, English, German, drawing, mathematics, geography, general culture, etc. We also have games during part of our free time. In the afternoon we have class for one hour and then we are free. There are big houses for the children; all of them belong to the Union OSE, which is a wonderful organization. Our houses have a general director who is very kind and the houses also have their own directors, who are also very kind. Our director also teaches gym and crafts. Now we are making pretty leather things. Before that we did basket weaving and we'll soon have a workshop for carpentry and book-binding. Next time maybe I'll write part of my letter in English and you can do the same if you like with your whole letter.

We made a six hour auto trip through Paris, and we saw a lot of things. It is impossible to give you all my impressions of Paris.

(2)

I can only say that the song is certainly right: "Paris, thou art the most beautiful city on earth."

We went to some of the Paris museums. We went to the zoo, too, where even the wild animals are only kept away from people by deep ditches of water. There are no cages. If possible we're going to Versailles soon and some time maybe to the sea shore. We have also been to the circus already.

Just now the children from the "St. Luis" are with us - the boat that was not allowed to dock in Cuba. These children are going to have their own home. My parents hope they will be able to go to England soon: let us hope that they will make it.

A few weeks ago we had a big opening festival in one of our homes. There were about 400 people and also some barons. We did a lot of funny things. I was a negro and they painted me with cocoa. I was dressed in a straw skirt and a necklace of dried macaroni, which was supposed to be the bones of my

Ә Open Access. (C) 2021 Frank Jacob, published by De Gruyter. (c) BY-NC-ND This work is licensed under the Creative Commons Attribution-NonCommercial-NoDerivatives 4.0 International License.

https://doi.org/10.1515/9783110679410-013 
victims. I played songs on the harmonica and on the accordion and I sang in a chorus. We had a lot of parties, lemonade and ices.

Ernest, a 14-year-old boy from Frankfort am Main, wrote the Above letter to a friend in London. Ernest came to Paris with the second transport of refugee children from Germany and Austria. In February 1939 the first children arrived at the Montmorency home of OSE.

"Are Jewish children really allowed to go to the park?" Such was the astonished question of the children when they learned they were to

play in the park of the Villa Helvetia. They were soon made themselves perfectly at home both in the villa and the park however. They rapidly recovered from the painful shock they had suffered from the persecution of their family and friends. Before long, happy laughter filled the houses and bubbled up to the tops of the centenary trees in our gardens.

At the end of June came the children of the St. Luis - the fugitives who had wandered around the globe and then been disappointed in their hope for a haven in Cuba. A little later we welcomed several children from Czechoslovakia, then some from Poland; a number of them had lost their fathers in the war, some of their mothers could not be found. We also took in other children whose fathers were serving in the armies of the Allies.

Today, one year after the opening of the first home, we accommodate in the four OSE Union homes for refugee children, 283 youngsters. 21 children are lining at the sea shore (18 in Ares and 3 in the "Preventorium" of Archon), which brings the total up to 304 children. The following letter from another child:

“. .. When Mother left me at the station, we had to lie down. But I could not sleep all night. When we got to the home, they were glad to see us. Oh, I forgot something! We also took a trip on the bus that was wonderful. The home is very nice. The children are very kind to us. The house is very beautiful. The walls are decorated with painted flowers and there are curtains on the windows. The food is good. Only there is too much milk in the coffee, but that does not matter. For about two days we were in the Rothschild hospital. Now don't get worried and don't think I'm sick. Everybody was there

\section{(4)}

and nobody was sick. I'll explain it to you. They do ot so no sickness can spread among the children of the home."

This description comes from a ten-year-old-little Viennese girl who wants to give her parents some idea of her travel experiences and her arrival in Paris and the home. The children all stayed in the Rothschild hospital for a few days, they 
were examined and vaccinated against small-pox, and were thereafter assigned to the different homes.

The educational task that faced us was of a complex nature. We had to keep in mind the previous lives of the refugee children, the particular circumstances of their coming to the home and the probable living conditions that awaited them later on. These children had to bow suddenly to the fate of the prosecuted - forced upon them with abruptness and cruelty.

They had grown up and been educated in the atmosphere of German culture; now they had to learn to understand French culture, its conception of humanity, of the Rights of Man, of its bond with all other nations. Many of these children were waiting for their parents to take them overseas - somewhere. We must prepare them for their future fatherland and at the same time help them carry with them this cultural and intellectual wealth. Our task was complicated by the fact that in many cases the children had been without regular schooling for years. They were no longer accustomed to study of gymnastic work of any kind.

First of all, however, we had to consider the mental shock the children had suffered - the consequence of persecution, of separation from parents and friends, and of emigration.

$[. . .]^{283}$

(6)

Sometimes despair drives an adult to burden a child with moral conflicts and problems it cannot solve. Thus an elder brother writes to his sister:

“. . . Write very often to your poor mother, as often as you can, so she won't worry. do anything you can to help your dear mother, for you know what she has had to suffer for you. If mother could not get the immigration visa, it would mean saving your father from Dachau. Daddy

must at all costs get out of there because you know poor dear father is very delicate. Show your tears and ask for help, for there is no other hope. Say you still want to have a father and you still want to see all your family. I imagine that is only you could get a visa, Father would be saved from torture. How unhappy he

283 Page 5 and parts of page 6 are left out here to avoid unnecessary redundancies, as letters are cited that have already been cited in other writings. 
must be to be imprisoned so long and not be there when you, dear J. and I left. He must be thinking of mother, too, how she must torture herself and go without food and sleep, getting weaker every day. I'm sure he is thinking of us all. Maybe you've heard that two thousand expatriated Jews have been sent from Vienna to the Polish frontier and there they don't know where to go to. They can't take anything with them, everything has to be left behind and, on top of it, people are beaten and go through a lot of other things too. It is not certain whether Poland will let the Jews come in. It would be awful, these people straying around in all directions, not knowing where to go; they are not allowed to go into Germany or Poland either. Lots of them would like to die; there will be sickness because of lack of food. The lord protect us so that poor mother and our dear sister don't have to go through all that. I don't want to write anymore because I am crying already and anyway, I don't want to make you sad. But look around and see whether you can't help your mother."

These children arrived at our homes burdened by anxieties, haunted by thoughts beyond their grasp. Our first task was to make them "children" again in plain words, to make them happy.

We believe we succeeded in this. And that success gave us the more pleasure because we knew that their feeling at home with us did not mean that the children were estranged from their parents and families. Parents' visits were sometimes trying. The difficulties were tenfold in a house where most of the children could not see their families.

As to writing them, few children did so regularly and of their own free will, however great their affection for their parents. We asked each child to write home once a week; he might, of course, do so more often. Nearly four thousand French francs a month are set aside in our budget for this one item of correspondence. The outbreak of war interrupted communication by mail with parents in Germany, Austria, and Czechoslovakia. There is a moment we shall never forget, the terrible moment of silence that followed when we had to tell the children: "At least not for the time being you must not wait for mail from your dear ones." Thereafter we were able to resume correspondence, mostly through the intervention of the Red Cross. We wrote regularly every week. How many children did not receive any answers for six months at a time! Yet they continued to write.

Our second educational goal was to accustom the children once more to an orderly life, to develop their sense of social adjustment and discipline. They must learn what it means to learn. It would not have been a difficult task to cultivate in the children an understanding of discipline had we taken as point of departure their experiences in Germany - the blind obedience of the Hitler 
Youth, the rigid routine of their life, the ritual of the Hitler salute, which had so deeply impressed many of our boys and even some of the girls. This hocuspocus, their rejection as unworthy of such participation, made it all the more attractive. They would have been delighted to be able to play at "Hitler Youth" a little now.

That was why we tried to awake in the children a contempt for Prussian discipline and blind obedience. At the same time, however, we would work hard to develop in them a sense of order and comradeship, spontaneous social adaption, and fair play. We were astonished at the

ease and rapidity of our success. Our principal methods were tireless explanation and guidance, practical demonstration carried out in cooperation with the children themselves, and participation by the children in the administration of their own community affairs. We did not begin our collective work by making class rules, time schedules - cooperation however, was our idea from the beginning. "You see," we said, "we can't control you all the time and keep you in order in the house you may keep order yourselves." A little later: "Wouldn't you like to choose someone among you to see that there's no noise and disorder?"

"Here's a football for you, here is some other equipment, distribute them among yourselves so that everyone can enjoy them. You may make some one child responsible for taking care of them so that nothing gets lost. The football and all the athletic equipment are your common property."

"We may make an excursion tomorrow, when we come home we'll have to eat. So before we leave, wit down and peel the potatoes. Keep at it so it'll get done soon."

Many children same to us confidingly with their hopes, and yet there was in them a depression and embarrassment - a product of some hundred years of ghetto life, and recent years of persecution. "They stepped on us and beat us in Germany," a fifteen-year-old child told us on his arrival in Boulogne, where we had gone to meet the young passengers of the "St. Luis". "We only wanted to escape and wait in Cuba for our immigration visa to the United States, quietly, without any trouble. But they drove us away from there too. Then we went along the Florida coast. It seemed full of quiet and peace, but for us there was no port to dock in. Neither in America, nor in Haiti, nor in St. Domingo.

They sent telegrams to all parts of the world to get permission for us to disembark somewhere. Mow we can enter France. For how long? Where can we go next? What a life we lead!” 
No, these children could not be made happy just by a well-ordered home, by lawns and towering trees - which would not be sufficient for any child. It was necessary to convince them that the persecutions they had suffered were not the inevitable fate of the Jew, and that they must not simply search for a sheltered hiding place among other people, but courageously battle against all anxieties and difficulties of life. We sought to teach them that unremitting work, founded on the skills they acquired with us, would in the future enable them to forge their own fates. We sought to educate true men, free men, men of responsibility who understood their obligation to the community, men possessed of the industry and knowledge necessary that they might create for themselves purposeful lives.

At first our school had no definite time-table in the strict sense of the word. Each group had a daily French lesson and what we called "general culture". All the children living at the Villa Helvetia - there were about a hundred at this time gathered together for that lesson. We discussed the events of the day in our little world as well as those of the "world at large". We considered them in their relation to our personal lives and our future opportunities. On the arrival of the children of the "St. Louis," we made the trip to Cuba and back in our discussions. We explained why these American islands are called the West Indian Archipelago. This lead us to a discussion of the discovery of America and the age of exploration, of America and its inhabitants today. We discussed the possibilities of emigrating there and the necessity for learning in preparation for that

emigration. Following these discussions our English class was started.

When the story of the ship-wreck of the submarine "Squallus" and the efforts to save its crew was stirring the world, we too talked about it. We calculated the distance between our homes and the scene of the accident; we estimated the quantity of oxygen necessary for the rescue. This brought home to many children a realization of their lack of knowledge of figures. That week we began our classes in mathematics, graded according to age. We followed the efforts made to save the crew with the same new "diving-bell". We discussed displacement and hydrostatic pressure, and the juniors began their object lessons and the seniors their instructions in physics.

We stressed the courage, the quiet composure, the tenacity of the shipwrecked men in their submarine prison. We made clippings of pictures in papers and composed them into a "photo mural". We admired the courage and perseverance that could face such difficult circumstances and never lose hope.

Our aim was to mold character and willpower through a consideration of such examples within the framework of a humanitarian, ethical, and democratic education. In the course of our discussions of and their application in 
real life, we compared the acts of the military dictatorships which consider solely their own interest, with the generous proposal of the American government, which put at the disposal of all who needed it, the "submarine bell" just successfully employed. July 14th, the glorious French national holiday afforded a solemn occasion for speaking to the children about the Declaration of the Right of Man. In the morning we had a party for the children of all our homes in the festive garden of the Villa Helvetia; in the after-

noon we joined in the celebrations of the school children of Montmorency; in the evening we witnessed the bonfires of Paris and its suburbs. In the weeks that followed our general culture lessons were devoted to an explanation of the meaning of the Rights of Man. The problems created by the spontaneous collaboration of the children - troublesome sometimes, we admit it - were satisfactorily met by our system of "co-administration." Co-administration was in no way regarded as merely instructive play either by the children or the teacher; it was an important part of our educational program. On the one hand it is a method and the principal one at that - of moral education and character building. It is at the same time an inherent part of the deductive "Arbeitsunterricht" method. this method seeks to replace a superficial acquaintance with school subjects by real assimilation, and enable the children to develop their peculiar abilities with the help of the teacher.

In the middle of April, 1939, instruction began in the school of the home. For the first two months all classes were conducted in German exclusively, but every day two hours were devoted to the teaching of French.

Our first task was to put the children back to systematic work. There were some who had not attended school in Germany for the past two years preceding their arrival. We had just succeeded in reawakening their interest in schoolwork; we should have destroyed that interest had we begun our teaching in German, accompanying this instruction with discussions of our material in French.

After the first two months we adopted the French language for gym-

nastics and drawing, later for geography and French history, and finally for the natural sciences and mathematics. Thereafter, one day a week all classes were given in French, then three days, and beginning October 1939, all teaching was done in French.

Since we believe that a child over a certain age can not learn a language thoroughly without instruction, we gave the children systematic French lessons instead of depending wholly on the influence of the milieu. 
The little ones from 3-6 learned French quickly from their immediate daily contacts. Among themselves they soon spoke French almost exclusively, after 6-12 months. For many of them German was soon just a familiar language, for others a foreign language they knew. The children from 7-10 received systematic instruction as well as the influence of their surroundings. Their progress was also rapid. They soon understood French perfectly and made use of it more or less correctly in their contact with persons belonging to the home, but among themselves they usually used German.

For the older children, systematic instruction was all important. They too, however, had the advantage of daily intercourse with their French surroundings and have quickly enlarged their knowledge of the language. Every new acquisition can be practiced at once, while bits of knowledge are picked up from their French neighbors, and theoretical foundation given in class. Children of that age were soon to understand French and even express themselves in that language, but among themselves they nearly always talked German. we were never annoyed when the older children spoke their mother tongue among themselves. Emigrants entering a new country in compact groups always cling for years to their own language. We were of the opinion that our method of teaching would give results at least as good as if we had brutally

forbidden the use of German and made French the exclusive school language. Our experience justified that belief.

Some of the children who came with the first transport were received by another organization similar to ours. Their directors considered our method poor and used French exclusively in teaching as well as daily intercourse. Later we had occasion to talk to these children, some of which were transferred to our camps, and we observed that most of them did not speak French so well as our children. More important than the acquisition of language, however, is that no character building or moral acquisition would have been possible had we tried to instill our ideas with words unfamiliar to the children. On the other hand, once the children had grasped some of the conceptions of democracy and the French way of life, once they had gained some sense of security, of being at home, of being permitted to learn and work, once they understood the meaning of courage and perseverance, of responsibility, freedom and human dignity, then there was no difficulty in teaching them the French words for these ideas. To give them a better understanding of the inhabitants of France, its institutions and the country itself, we planned excursions and trips and some participation in the entertainments of the village children. These children joined in our games and we were on friendly terms with our colleagues in the neighboring 
schools. - After the outbreak of war it was not possible to continue the excursions to Paris which we had begun with the help of a group of car-owners, friends of the OSE. The first and only excursion of this kind was made with some thirty cars, driven by their owners and conducted by Dr. Ettinger. The preparation of this trip took weeks - the route we were to take was studied and sketched; the history of every spot, every house, every interesting monument were related, photographs were hung on the walls, detailed maps showed the loc-

ation of monuments.

The night before the excursion a movie about Paris was shown to the children. The trip was a big event. The children greeted each new landmark as if it were an old acquaintance; the names had for them a living background. We were at last becoming a part of the big world called Paris. After the trip we went on talking about Paris - we described the town, figured out her distances, spelled the names of her monuments, read her poets, sang her songs, and learned her language joyfully.

From the very beginning we tried to group all the class instruction around some leading idea suggested by our chats on general cultural questions. These chats were conducted by our general director once or twice a week in each of the three groups into which the children were divided according to age. The voyage of the St. Louis, the ship-wreck of the Squalus and excursion to Paris gave some idea which topics we chose and the way we treated them. We wanted to draw as many examples as possible from real life, and thereby help the children to understand the development of humanity and human culture, the technique of work, the framework of community life. This was to the child the means of adjusting himself in the more or less restricted circle in which he actually lives, and of adjusting himself later on when faced with more complex situations with nothing to fall back on except his own resources. It has not been possible to carry out fully our plan to group all instruction around one central theme suggested by the general culture discussions. First of all the time for preparation was much too short, so that we could not assemble all the material necessary for teaching all subjects according to this method. Instruction began almost immediately after the opening of the homes; we had to con-

-form as quicky as possible to the material given in the French elementary schools and prepare the children, insofar as possible, for the same examinations. Though the French teaching staff followed our experiments with friendly interest, we could not in so short a time complete quick preparation fror the 
State exams with the kind of instruction that centered about our general cultural themes.

In January 1940 our school organization were partially changed. Thereafter $75 \%$ of the children of school age attended the public schools at Montmorency and Eaubonne, while $25 \%$ of the children attended our own centralized school in the ville Les Tourelles. The children made good progress in the village school. Seven of them reached the head of their class, three were second best, two ere third best. There was even one class where the five best pupils were our children.

Seven of our youngsters went to high school in Enghien. There too one was at the head of his class, another was third best. during school hours - the same in our school and the public school - we tried to give practical help to those children lacking sufficient knowledge of French to progress properly in their studies. During free periods and on holidays all the children got supplementary instruction in their favorite subjects, whether it was "general culture," foreign languages, handicrafts, music, sports, outdoor games or gardening. Our home school had three sections. The first was the nursery for children of pre-school age. This whole group was installed in "the little camp." The children learned about everyday life, especially daily hygiene. Morning gymnastics, a feature common to all our homes were in the form of games and were accompanied by songs. The children, even the three-yearolds waited on table and did various chores.

Among the chief subjects were rhythmic gymnastics, singing, handicrafts (tearing and cutting, paper-pasting, modelling). We often made use of Decroly and Montessori material, without, however, following any of these methods exclusively. Tables, chairs, brooms, all equipment was of proper size for use by the children.

The second group was that of the school-age children. The five forms corresponded approximately to the public school grades. The subjects and methods followed a syllabus checked and approved by an inspector of the Academy. All the children in this group, like those of the vocational classes, received preparation for the "certificat d'etudes". We felt that the Daalton method was best for the initial instruction of children of widely varying levels of knowledge. All the pupils of one class, however, were soon able to follow the same program. We gradually introduced group work and thus made common use of our time. At the end there were five homogeneous classes with 15-25 children in each; it was possible in such classes to give attention to the peculiar abilities of each child while at the same time following a class program. The class of beginners was subdivided into two groups of 8-11 children each. 
Our chief educational principles were inspired by the Viennes school reform, which sought to keep school instructions as close to real life as possible. The most attention was paid to manual instruction. The three lower classes had lessons in drawing and painting, drawing and modelling. In the fourth and fifth grades the children had elementary vocational instruction. In the fourth class nine of our girls attended the dress-making workshop, six boys took carpentry, these classes were given twice a week, two hour each.

In the fifth grade the nine girls and eleven boys took beginner's courses in tailoring, dress-making and carpentry, three hours, three times a week.

All the children worked on our flowers, fruit and vegetables. The youngest had 2-4 hours of gardening a week, the older ones 4-8 hours. The third group, the one for professional training, received 20 hours of practical work and 19 hours theoretical instruction - ie French, literature, mathematics, history, geography, natural sciences, history of art and sports, etc. Aside from their professional training the children learned some other manual skill, usually gardening. For this the older students used some of their theoretical instruction time, the others used extra-class time. This secondary manual training was in some classes a bare outline of the rudimental principles; in other cases it was a really complete training for a second profession. Our shoe-maker apprentices, for instance, had 16 hours a week of shoemaking and up to 12 hours of horticulture. In addition to 8-12 hours of theoretical instruction. We used this system to compensate for the professional drawbacks of the shoemaker's trade and to give our future shoemakers a supplementary means of making a living. We gave the factory hand a healthy enjoyment of work with the soil and the possibility of putting this knowledge of gardening to economic use if necessary. We had four workshops for our apprentices where they could acquire real skill. Eleven girls learned dress-making, sixteen boys joinery, fifteen children - boys and girls - studied gardening, and four, shoe-making. The shoe-makers took gardening as their 2nd handicraft, the carpenters and dress-makers also received some instruction in gardening, the boygardeners in carpentry and the girl-gardeners in dress-making. The carpenter's workshop and the gardening

course were instituted by the ORT; they directed it within the system of our school organization. The other workshops were under our direction. We planned to open with the ORT, a workshop fpr leather tooling, polishing and pasteboard work. During and after school hours our shoe-makers and dressmakers did repair work for our homes. A course in making posters and designing on tissue was part 
of the regular work for boys and girls, giving them further preparation for the learning of handicraft.

At the beginning of the second year our homes opened a cooking class. Before the war started we had intended to give this course in a specially equipped room, but the space we hoped to use in the Villa Helvetia became an air-raid shelter and we had to allow the use of our own kitchens.

Shortly afterwards we arranged for a course in professional dancing, under the direction of Mrs. Eduardova. Children who showed some special abilities in the regular dancing class and rhythmic gymnastics had the opportunity to get professional training.

We also sent one boy every morning to the "Cordon Bleu" cooking school to attend their theoretical classes. Two others went to a pre-apprentice school for electricians, another to a school of cinematography. We had English and Spanish classes for children whose parents intended to emigrate overseas.

“. . . Wednesday last Spanish classes began. Today we have a lesson again, and the pronunciation of the language is identical with the writing, I made up my mind to write down everything I learn and to add whatever notes are necessary for the pronunciation. In this way you will be able to learn Spanish with me. Take care of these notes, please. Each of you send me ten sentences for the first and ten for the second lesson. Let's hope I'll be able to help you learn Spanish

this way. The pronunciation is very easy and I hope you'll learn a lot in spite of the poor explanations . . . Now get to work!" (girl of fourteen to her parents.)

The whole way of life in our homes was intended to give the children the capacity to lead healthy and happy lives in harmony with the spirit of their foster country. Our work and organization sought to make them really free men, conscious of their responsibilities. The instruction given form Kindergarten up through the vocational training classes aimed at offering them as much knowledge as possible and at developing their occupational abilities fully. The choice of and preparation for a profession was the more necessary to these children because thy must struggle for a livelihood with nothing but their own abilities to keep them going. There was no family tradition to guide them, no parental success or connections to smooth their way. Their studies - except in the case of the college students - were not exclusively brain work. They helped bring the future manual workers up to the very highest intellectual level possible and make of them educated people.

So guided and trained, our children one day would, we hoped, become something other than crippled intellectuals or ill-famed Jewish second-hand dealers; we hoped they would become intelligent workers of the soil and in the 
factories or skilled artisans. Every three months each child got a report on his development. We did not give marks. A kind of grade was given by the letters A to E, each letter corresponding approximately to 2 points in the usual French classifying 0-10 system. But the important feature of our reports were their comments. There were 24 different evaluations, something like those used in American schools. The subjects were grouped into categories, manual work far from being neglected. Social adjustment was judged

as to manners, cleanliness, politeness, helpfulness, comradeship and co-operation. Under a special heading we noted in which direction the greatest progress had been made and where improvement was most necessary. The above remarks and the following list should make clear that our reports aimed rather at encouraging the child's work than at passing final judgement on the work done.

NOTES OF PROFESSORS AND COUNSELORS:
A. /8-10/ very good
B. /6-8/ above average, good
C. /4-6/ average
D. /2-4/ below average
E. /0-2/ unsatisfactory

\section{APPRECIATIONS:}

1) does his very best

2) is attentive and hard working

3) takes pains over his work

4) grasps things easily

5) is interested in the subject

6) expresses himself very well

7) concentrates on his work

8) shows perseverance

9) prepares his work well

10) shows comprehension, application and perseverance

11) shows initiative

12) shows imagination

13) could make greater efforts

14) is lazy and inattentive

15) does not take great pains

16) shows no understanding of the subject 
17) is devoid of interest

18) has no ability to express himself

19) superficial in his work

20) is without perseverance

21) does not prepare his work

22) shows lack of knowledge caused by absence

23) is not very bright

24) shows lack of imagination

A psychological and physical file was kept on each child, a kind of history of his whole development. Aside from the usual questions as to the condition of the child, there were questions concerning his social and intellectual development, and others in connection with the problems of emigration, separation from parents, next of kin, friends, familiar surroundings, and also the problems of adaption to the new milieu. We can mention here only that nostalgia played an extremely small part among the children of our homes. Doubtless that was a result of our therapeutics rather than a diagnosis - remark once made by a doctor who had visited our homes. We had forms with a prepared series of psychological questions worded precisely and briefly. It proved a good idea to furnish the teachers and counselors also with detailed explanations impressing on them the importance of regarding their answers for the development of each child, including their statistical value.

Later we changed these forms into note-books, in which more detailed questions and answers could be given. The health conditions were generally very good. We had no epidemics. Despite the contact with the village and other schools and workshops we had only one case of scarlet fever which the child caught during vacations when visiting his

mother. Any child with fever, whether the illness was contagious or not, was instantly separated from the others, medically supervised and tended. All the children were vaccinated against diphtheria and whenever it was considered necessary, their inoculation against smallpox was renewed. All the children were checked as to their cutaneous reaction to TBC. Those of pre-school age showed negative reactions; of the children under twelve there were twenty-one positive cutaneous reactions; of the older ones forty-two out of one hundred and four. Every child was examined by our doctor; in the doubtful cases where the children had frail constitutions, she asked the advice of specialists and x-rays were taken. 
We distributed 27 pairs of spectacles to our children and obtained 15 archsupports for flat-footedness. in gym we insisted strongly on exercises that strengthened the arch of the foot. These exercises were repeated daily during morning gymnastics.

At least once a month a dentist came to our dental office in the villa "Les Tourelles" to treat the children. Every child who had been ill once had a medical record card to which future illnesses and the treatments necessary were added. Serious or chronic illnesses were also noted on their psychological and health cards; the same applied to inoculations and reactions thereto. The monthly remarks on changes in weight and height provided a constant check on the health of the child; sometimes the doctor of our homes saw reason to intervene. In each of our dining rooms was a list of children who should gain weigh tand therefor get special foods; vitamins, more sugar in their chocolate, more butter on their bread etc. The first year after the opening of our homes we had the satisfaction of seeing many increases in weight, sometimes up to 20 lbs.

An ultraviolet lamp compensated for the lack of sunlight during the

winter months. Constant instruction on care of the body - brushing the teeth, washing and bathing, setting-up exercises in the morning, exercise through gardening, and outdoor games and sports, having the dormitories, dining rooms and work shops properly ventilated, vigilant medical supervision, immediate segregation of children with fever and conscientious medical treatment, certainly did much to diminish the amount and seriousness of illness among our children. We should like to mention here that three of our children whose frail constitutions made the susceptible to illness were sent to a preventorium at Arcachon, while eighteen children I delicate health got some rest at the sea-side in Aras.

The attitude of our children toward the doctor and their reactions when it was necessary for them to receive medical treatment of some kind demonstrated admirably the principle of unity of physical and mental education. Superstitious fear of illness did not exist among our children; they were not afraid to say they felt unwell. They were not afraid of medical examinations. They did not resist therapeutic or preventive measures and endured without protest the sometimes painful treatment of the dentist. Even the youngest did not refuse to take medicine. We were much impressed when all our children bravely presented themselves for anti-diphtheria vaccination after the doctor had given them a little lecture on the subject, warning them that they might have to endure considerable pain and high temperature after the three vaccinations. Of course there will always be timorous and frightened children and those specially 
sensitive to pain, but the atmosphere of confidence created by explanations given with complete frankness helps to overcome the resistance of the more fearful children. In spite of the painful injections and bitter medicine given, and in spite of the quick recognition of simulated illness among school-

children, the doctor was loved by the children. The same was true of the counselors and teachers, who could not allow the children to do everything they wished, who had to demand work when they wanted to play, who sometimes had to inflict punishment, every child felt sure that he was loved and that our aim was his happiness; he understood that it was sometimes necessary to take unpleasant measures against him. The teachers and counselors were his good comrades; they always kept their word.

The free hours were very carefully organized. In most case the children themselves did the necessary planning, but outsiders to the Homes were also permitted to participate. The greatest disadvantage of community education is that the entire life of a child in all its many aspects, is lived in the same environment. The problems of life outside the group never reach the child. The Home provides school, family, friends, comrades, athletic groups, and travelling companions - the same counselors always guide them, the same friends surround them, the same problems face them. These problems are aided in their solutions by the counselor who either impose the solutions on the children or recommend such solutions in order that the discipline of the Home may be maintained.

The children are divided into classes and home-groups. The classes are composed of children from our various homes. Only the little ones have classes in their own home; the older children suffer the inconvenience - and sometime even the danger - of a 30-40 minute walk to counteract the staleness of the home routine that isolates the youngsters so completely from the outside world.

Twice a month, on Sunday afternoons, the oldest children of all the homes gathered for youth meetings which they planned and organized

themselves. On one of these afternoons the children heard a lecture on the aims and organization of the OSE Union (by Dr. Minkowski); another meeting was devoted to spiritual and physical instruction, a third to a discussion of pupil's examinations and reports. They also discussed Palestine and youth movements, they recited the "Malade Imaginaire" by Molière. We introduced them to the "Barbier de Seville" and "La mariage de Figaro," singing and playing them airs and choruses from both operas. The children arranged a concert, a ping-pong competition and a big athletic meet. 
Their visit to the studio apartment of the great sculpturer Aronson made a deep impression on the children. Though sculpture readily impresses children and young people, their response is generally ofa superficial nature. But this great artist made a really deep impression by explaining the technique and motifs of his creative work. It is interesting to note that some of the children asked us immediately after their visit to discuss art in its various forms. We tried to form a children's orchestra and cultivate their desire for music, but we did not have much success. The smallest children, those from 3 to 6 , formed an orchestra with very simple instruments, such as whistles, triangles, drums and trumpets. Their exercises served to awaken in them a sense of rhythm, an ability to fit into a musical ensemble, and pleasure in harmony. The second orchestra, not far advanced, was supposed to be in the transition orchestra between the kindergartners and the older musicians. This second orchestra instruments capable of two or three notes. The third group-orchestra consisted of children who could actually play an instrument. We much regretted being unable to give the children music lessons, but we did gather a large group of flutists, accordionists and mouth-organists that grew constantly, one child teaching the next.

Sometimes the oldest children spent their free time working up a program of entertainment for the younger ones, which helped the smaller children get rid rid of the feelings of always being the little brother or the little sister. The children's council of the homes decided to arrange special afternoons for the youngest children. Once a week we had dancing class for the older children. Rhythm exercises compensated for the many hours which they spent sitting in school, always using and tiring the same muscles.

We loved celebrations with or without occasion. Every birthday - and there was one nearly every day - was a good excuse. A cake with as many candles as the child had years, some sweets, a short speech - then the birthday child was lifted up in the air while the other children sang songs. The birthday child then received little presents from the other children and his counselor; sometimes we also laid the table with packages sent by the parents.

The 14th of July, New Year's Day, Passover, Chanukah and Purim were occasions of of special delight. For educational reasons we were very anxious that at these celebrations no particular groups or individuals should overshadow the other. The children and counselors all worked together on the plays they put on, taking turns in the various parts. Different children were chosen for the leading roles each time. In spite of careful rehearsal and preparation and good performances, there was no straining after effect. We judged this kind of work from an educational rather than an artistic point of view. 
We have already mentioned the administrative cooperation of our children. There follows a list of the regulations of the Homes. Most of these regulations were edited by the children themselves and reexpressed in their own words. For educational reasons we wanted this editorial work done. It gave us good opportunity to discuss with the children

the fundamental principles of our Homes and to make them understand that the system was one of co-administration - we did not use the common term "self-government". The children understand perfectly well that it was impossible to hand over to them the management of our Homes, since the task of an educational institution is, first of all, education. They understood that their education came first and that its requirements necessarily affected the administration and limited the freedom of both adults and children.

Co-operation and co-administration are always the most important links in the chain of educational methods. They cannot, however, led an independent existence, but must dovetail with educational principles. We did not want to give the children the illusion that they possessed unlimited freedom; we sought rather to define with them the limits of this freedom by following principles in which the children acknowledged justice, so that co-administration was not a game but real "business". Our Home-Rules laid down principles with which we required compliance, but no details were given, since they must change constantly.

The Constitution of the Children's Homes of the OSE Union:

All the children and adults who lived in the children's homes of the OSE Union formed a community which directed the life of the homes by democratic administrative cooperation. This community was one part of the great community of all human beings; it was proud to live among the French and was conscious of belonging to the Union OSE, agency of assistance to Jews.

The democratic rights, as well as the duties, of the members of our small community were the same as those in communities in which we were contained. The liberties and rights of our members were limited by vol-

untary subordination to our duties to all other human beings, to the Nation in which we lived and the association to which we belonged.

The Rules of the Constitution:

I. Only children over 8 years have an active and passive right to vote. A child can be selected while absent.

II. The elections shall be secret, unless there is unanimous decision to the contrary. 
III. a) Delegates: Each room has a delegate, who shall live in that room. The task of these delegates is to inspire a spirit of comradeship and encourage respect for tidiness and the property in the room. They have a right to remind their roommates to attend to their duties. b) Group Committee: This consists of 3-5 children, elected by the group. Counselors responsible for their own group participate without being elected, however. The Group Committee can act without appealing to the Group Meeting, but it must afterwards obtain its consent. The group meets each week with the Group Counselor in the chair. Extra meetings may be called with the consent of the Group Committee.

IV. Home Committee: is elected by the members of the house. It consists of 5 children, the head of the home and one counselor, who is elected by the other counselors. Among the five children there should be, if possible, two younger children.

Rights and the Duties of the Home Committee:

It has the right to take part in organizing occupational activities, free hours and celebrations; it can express desires and propose modifications. The Home Committee controls the activity of the Group Committees. The President of the Home Committee is the child who receives a majority vote at the Home elections.

V. Home Council: This is made up of all Home Committees and the General Manager. The Homes Council is the central organ of cooperation in all the homes. It supervises the activities of the other committees. It meets every two months or, under extraordinary circumstances, when a Home Committee, $1 / 3$ of the Home Council, or the General Manager requests a meeting. This Homes Council is presided over and represented by the Presidents of the Homes and the General Manager.

VI. The Disciplinary Council: An accusation or complaint against a child shall e considered from the point of view of justice as long as it does not involve educational or administrative questions. Penalties shall be submitted for approval to the General Director of the Head of the Home. In doubtful cases, the President of the committee discusses the question with the General Director. A member of the Disciplinary Council cannot assume any other duties.

VII. The Court of Appeals: Consists of the Presidents of the Homes Committees. 
VIII. Term of office:
a) Delegates
6 weeks
b) Group Committee Members
3 months
c) The Home Committee
6 months
d) Homes Council
6 months
e) Disciplinary Council
5 months

We had the best experience with our co-administration and the disciplinary council. The children approached the problems of co-administration with much dignity and earnestness. Of course, much time had to be given to explaining the necessity of handling with such disciplinary

case with justice and making the children understand that certain acts must be censored or punished in certain ways. This time was not wasted. In our opinion, real educational benefits can be attained only if the children comprehend the necessity of working and submitting voluntarily to certain restrictions. The poor animal tamer can easily do without the co-operation and co-administration of the children, but the true teacher cannot. Our children were willing to make decision and to do the work we thought necessary and to execute justified punishment. As a matter of fact, we had to prevent the children from overdoing punishment in their youthful eagerness. When we were compelled to interfere we always made sure that the guilty child understood his offense. We explained to him the cause of his bad behavior. It was often painful to see how unhappy the child was and how frightened at his "crime." The effect of this educational work was lasting. Punishment by the grown-ups in most cases created in the child a sense of being terrorized and an inner resistance; he felt himself unjustifiably punished and therefore excused himself and minimized his offence. The hearings before the Disciplinary Council worked remarkably well in eliminating that reaction. The defendant's opportunity to talk and explain his act and the circumstances under which it occurred made the child forget to sulk. He understood his mistake.

In most cases a simple warning settled the matter. It is such more agreeable to recognize and praise merit than to admonish, but we refrained from too much praise in order not to diminish its effect. Simply giving encouragement when necessary.

It is chiefly the relationship between the children and the adults that creates the atmosphere of an educational institution. The children

had confidence in our acts and in our promises, but we had to win this confidence, for their initial distrust was great. When we first announced that some event would 
take place on a certain Thursday, the children busily whispered to each other all through Tuesday, Wednesday and even Thursday morning: "It's not really going to happen." At first when we said "yes" they retorted: "You, you always say yes." When the doctor first promised that this or that would not hurt, nobody believed her, and when we first said no exceptions would be made for anyone in a certain connection, all the children were convinced that the others would be preferred. But we kept our word and explained the reasons when we were unable to do so and the children's confidence came readily. We never concealed our own insufficiencies, we were the first to acknowledge them and in that way we escaped the mockeries and the mischief of the children. What was more, our frankness won their respect and awakened in them a chivalrous attitude toward weaknesses, which we should never have been able to hide anyway. Very seldom, only in the beginning, did the familiar form of address lead to impudent and arrogance. We had to make very little effort to stop these indiscretions, for the other children considered it extremely unfair to abuse our good fellowship, and they themselves put a prompt stop to the "freshness" of any youngster. Despite our comradeship with the children, we never lowered us to their level. That would have made us ridiculous. We always insisted on the right to lead our personal lives. It was a community of children and grown-ups; every individual had his right to individual life, joining with the others to build a well-loved community.

One small fact is interesting from an educational point of view. The walls of our house were never disfigured with pencil marks; there were no designs or drawing, even in the lavatories, though we never mentioned the subject.

At the beginning of the war, eleven of our male counselors left us. Some of them had to enter the army, some the camps set up for all foreigners. Their departure coincided with the opening of a new home, "La Tourelles." New children arrived. New houses was not ready. The workmen were also called to the army. The first air-raid alarm in France came, and we had to transform our cellars into shelters. During these days the women members of our staff, despite their personal wartime anxieties, did remarkable work. For a while we had only one cook and one chairwoman in Torelles. The children offered their help and it was so efficient that we were able to maintain our old standard of living and even make improvements. During the first two months of the war, Mrs. Papanek took over the General Director's work, in addition to regular duties. Within a few weeks after war started, 53 evacuated children were taken into our Homes for a limited period. They were later sent to other homes.

After the outbreak of war three of our children were placed with families. 27 others were transferred to the Southern French OSE Homes in the Department 
de la Creuse; 8 emigrated to the United States and 4 others to South America. One child went to Africa and another to Yugoslavia. One deaf and mute girl who spent some time with us working with the others in our workshops and attending classes, we later placed in the Home for the Deaf and Mutes. She apparently had been very happy with us. She could speak a few words - "merci," and "au revoir" by the end of her stay.

Divergent Jewish views did not disturb the internal affairs of our Homes. Only educational consideration played a decisive role. We could not raise Zionists, Nationalists, Assimilationists, or Orthodox Jews. Their parents entrusted their children to us, and we sought to develop them into healthy people, sound in body and in mind, to encourage

their talents, to prepare them as we could for the struggle of life, and to guide them to an independent, honest, and sincere way of life. When they returned to their parents, or were thrown on their own resources, they could follow their own beliefs. This does not mean that our educational work was done in a vacuum. It strove towards the noble goals mentioned in the preamble of the Home Constitution: respect for human freedom and dignity and constructive living in the nation which had received us so generously.

The children were aware of the differing ideals of their instructors and comrades. There were representatives of nearly all opinions among us - we asked them no questions, respecting their honest convictions.

Our understanding and respectful approach made it possible for us to conduct a Home of orthodox children in accordance with their customs. The children of this Home, "La Chesnaie" did, however, go to school with the other children. They took part in all the games and recreational activities and made friends with the non-orthodox children of the other Homes. The educational, economic and administrative direction of the Homes was in the hands of the General Director and we thus succeeded in coordinating the three phases of our work. All economic and administrative problems were subordinated to the educational, although the former were carefully considered.

Funds were secured and administered by the OSE's Children-Committee, whose Chairman was Baroness Pierre de Gounzbourg. Nearly a quarter of the funds spent for one year were given by the American Joint Distribution Committee. We founded the institution to sponsor refugee children, which also helped us obtain funds; the principles of this institution was enclosed. A reading will make clear that we sought to avoid any humiliation to either the sponsored child or his comrades. 
(35)

The annual expenses for one child amounted to 5.600 francs before the war, 6.500 francs during the war. By our methods of collecting funds, centralizing administration, applying our educational ideas and organizing the Homes, we sought to raise our work from the level of private charity to that of social welfare.

We hoped that when our own children left the Homes of the OSE Union they would not have the oppressive sense of being reared in a charitable institution. We hoped that they would grow up as free men and women who were assisted and instructed by an organization which was happy to have been able to give them the help they needed to prepare them in some measure to make their way courageously to a new future. 